M. F. Kessler and V. Večeřiková reported a variety of physical and physicochemical measurements on cokes and related them to hardness and reactivity. J. H. Ehretsmann and R. C. Seymour had studied the gaseous products and thermochemistry of the formation and decomposition of surface oxides on charcoals. H. Guérin and M. Bastick demonstrated the importance of microporosity during gasification of coke between $800^{\circ}$ and $1,000^{\circ}$ C. C. Heuchamps, L. Bonnetain, X. Duval and M. Letort showed that the apparent energy of activation of the combustion of graphite varied with temperature and extent of combustion, and was a complex function of heterogeneity, porous structure, impurities and reaction mechanism.

It is appropriate after three successive occasions when the burden of organization has largely been borne by the Dutch State Mines to add an appreciation of the magnificent arrangements made by the scientific and administrative staff of that body. The never failing resourcefulness of $\mathrm{Mr}$. W. J. R. Berkx in all aspects is especially worthy of mention. The moving spirit behind these conferences has been the president, Prof. D. W. van Krevelen, and it must be recorded with regret that he has now resigned the presidency in view of his pending transfer from the coal to the plastics industry. To mark the occasion, tributes were paid at the end of the Conference by R. Loison, I. G. C. Dryden and M.-Th. Mackowsky on behalf of the French-, English- and Germanspeaking sections of the audience. Prof. van Krevelen's impact on coal science has occurred only within the past ten years; yet, owing to the original and prodigious output of his research teams, he has left nothing unchanged. The Conference wished him every success in his new field of endeavour.

I. G. C. Drydey

\title{
CURRENT RESEARCH ON NOISE
}

$I^{\mathrm{T}}$ is only within recent years that acoustic noise, once studied simply for its effect on hearing and annoyance, has proved important in physical systems. Noise has long been a source of annoyance; its effects on working efficiency have been clear when it has interfered with speech communication, less clear in causing fatigue ; and for years it has been realized that continued excessive noise can cause permanent deterioration of hearing-_boilermaker's deafness' has long been known.

These effects are still with us, in intensified form, since with the increased power of machines to-day, noise-as a by-product of this power-is increasing also. For this reason, the physical aspects of noise have come to the fore. The intense fluctuating pressures in the noise field near a jet engine can fatigue and fracture the structure of the aircraft. The forces on a missile flying through rough air may consist largely of random constituents, which need to be analysed in some detail to determine whether any frequencies are present which may damage the equipment in the missile. Such analysis is, of course, similar to that used in many other fields, such as radar; and thus acoustic noise problems find their counterparts in other studies.

These different aspects of noise were explored recently in two symposia held by the Acoustics Group of the Physical Society. The first, "Recent Studies of Noise Problems", was held at the Imperial College of Science and Technology, London, on March 24, with four papers on psycho-acoustic problems, and two on physical acoustics.

\section{Human Response to Noise}

The general effect of the first group of papers, curiously, was that work in many aspects of the subject culminated some five years ago in the United States, and little advance has been made since. This was particularly true of the account of noise and hearing loss given by Prof. W. Burns (Charing Cross Hospital Medical School). This subject is still heavily in debt to the classic report $(Z 24-X-2)$ of the American Standards Association, and little more has been learnt about safe noise-levels. However, work is continuing on the effect of age on normal hearing; this will give a better 'base-line' for the estimation of hearing damage, and is a subject on which the American report was not very satisfactory.

Procedures for evaluation of the loudness of a complex sound, however, have progressed very little in any country. This was discussed by Mr. N. Fleming and Mr. D. W. Robinson (National Physical Laboratory). The National Physical Laboratory equal-loudness contours remain unchallenged, but they are for pure tones only. The various ways of dividing and weighting the spectrum, in order to calculate loudness, do not seem very productive; while annoyance is a factor even harder to measure objectively.

Much of this difficulty may be due to the fact that pure tones have in the past been considered of major importance. But as speech, and even music, are in effect successions of transients, many noises should be considered in the same way; and a study of the aural effects of transients may be a more fruitful approach.

The point was, however, made by $\mathrm{Mr}$. Fleming that the multiplicity of criteria in American psychoacoustic studies may not be needed. He pointed out the equivalence between the 'equal-annoyance' contours for community noise, and the readings of representative noises on the $A$ weighting of the sound-level meter. The $A$ weighting is a valuable one for many approximate loudness studies; it is frequently used on the European continent in trafficnoise problems.

Further points on community reaction to noise were dealt with by Mr. H. J. Purkis (Building Research Station). The techniques for evaluating the annoyance of different types of noise, developed in America some years ago, still appear generally valid, although some alterations to suit the differing susceptibilities of English communities are needed. It is hoped to collate several case histories of noise annoyance, with the view of obtaining more applicable data.

Dr. D. E. Broadbent (Medical Research Council) spoke on the effects of noise on working efficiency. This is a field in which it is most difficult to obtain conclusive results. A pattern is, however, beginning to emerge, connected with the effect of noise in interrupting attention; noise often seems to interfere with tasks necessitating short-term memory. An overall level of $90 \mathrm{db}$. appears critical, and it is found 
that, whatever may be the effect on efficiency at work, noise increases, for example, wastage rate, and number of mistakes.

\section{Physical Acoustics}

Two papers on physical noise problems were presented. Mr. D. M. A. Mercer (University of Southampton) dealt with the difficulties inherent in obtaining accurate measurements of aircraft noise. Such factors as ground reflexions, size and behaviour of source can cause errors of a few decibels ; comparisons of, for example, the performance of jet silencing devices may be quite misleading if these precautions are not taken.

Diesel engine noise was discussed by Dr. A. E. W. Austen and Dr. D. Priede (C.A.V., Ltd.). Speed and swept volume have been related to sound output; there is little variation with load, due to the characteristics of the diesel engine. A quite thorough survey has been made of the vibration of different surfaces of the engine and their effects as noise producers, and sound-levels calculated from these are consistent with measured noise-levels.

\section{Aspects of Noise Analysis}

The second symposium, on "Now Techniques in the Analysis of Noise and Vibration", was held in the Physics Department of the University of Southampton, as a joint meeting with the Institute of Physics. The attendance of about 150, drawn from diverse fields of physics, engineering and electronics, indicated the considerable interest in the analysis of 'noise in the widest sense'. The emphasis was on new and projected techniques; standard bandpass filtering methods received little attention.

The meeting was opened by Mr. R. A. Eades (Signals Research and Development Establishment, Christchurch), who described the speech spectrograph, an instrument capable of examining and analysing short samples of sounds, and presenting the analysis in a manner similar to that of the visible-speech techniques. Mr. Eades made the important point that, in much of this work, bandpass filters with sharp cut-offs are not desirable, due to the 'ringing' they give; the lowered frequency discrimination of a filter of Gaussian or tuned-circuit characteristics is amply repaid by freedom from ringing.

Mr. G. J. Herring (Royal Aircraft Establishment, Farnborough) described an analogue-to-digital con- verter which converted a fluctuating voltage into an input suitable for a Pegasus digital computer. The computer could then be used to make an analysis of the input wave-form. This method was developed because purely analogue methods had proved unsatisfactory. This paper, and the previous one, led to considerable discussion; it was clear that the problem of analysis of random wave-forms was important to many workers. One point, however, was that the distinction between wave-forms with and without a periodic component-a difference important to the statistician -was not always made clear; with consequences perhups of unnecessary difficulties in many analyses.

Mr. D. M. A. Mercer (University of Southampton) emphasized the practical point that, in any analysis, frequency discrimination, stability of estimates and ease of computing were all linked, and could not all be maximized at once; great care was needed in the planning stages of an analysis. Cross-correlation techniques were often able to give results unobtainable by straightforward methods.

Dr. G. M. Jenkins (Imperial College of Science and Technology, London) discussed the statistical implications of obtaining a spectrum via an autocorrelogram. It is desirable to examine the autocorrelogram itself before the Fourier transform process; in any event, some modification to it is often desirable, to obtain a more stable spectrum, but in addition much information is often available at this stage; and different applicable statistical criteria were described.

The ensuing discussion demonstrated much interest in the use of axis-crossings of a random function. Presumably there is a major theoretical breakthrough to be looked for on this topic ; but apart from this, theoretical and experimental studies demonstrate that axis-crossings carry most of the information of a wave-form (apart from magnitude, of course). The limitations of the method, however, are not yet known.

The concluding impression of the symposium appeared to be twofold: first, that 'noise in the widest sense' is a subject of considerable interest, and secondly, that there often appeared to be a considerable gap between the theoretical studies, and the work of those concerned with practical noise and vibration analysis. This leads, at best, to correct analyses obtained with unnecessary difficulty, and at worst, analyses which are meaningless. Closing of this gap would be of benefit to all concerned.

Derwent M. A. Mercer

\section{BIOSYNTHESIS AND SECRETION OF ADRENOCORTICAL STEROIDS}

T a symposium held on February 14, the Bio-
chemical Society gathered together a group of
investigators who described their own work and that
of others on various aspects of the biogenesis of the
adrenocortical hormones. In an introductory paper,
I. E. Bush described the chemical nature of the
steroids under discussion and the applieation of
various types of chromatographic procedures to the
separation and identification of these substances. An
important feature of steroid chromatography is the
very large number of possible compounds and the
danger of wrong identification if chromatographic
properties are relied upon to the exclusion of others.
This danger may be diminished by the use of numerous microchemical and spectrophotometric techniques. The former include acetylation or oxidation (notably the removal of the C-17 side chain) on the 10-20 $\mu \mathrm{gm}$. scale, followed by observation of the chromatographic behaviour of the product on paper. Spots of steroid on paper give various well-known colour and very sensitive fluorimetric reactions. On the physical side a wide range of correlations between structure and absorption bands in the infra-red region has been established. Ultra-violet absorption spectra in sulphuric acid and alcoholic alkali provide useful information which, in conjunction with paper chromatography and comparison with reference substances, may provide identifications almost as reliable 